\title{
Positive tracheal SARS-CoV-2 RNA test after three negative SARS-CoV-2 RNA tests in a patient with COVID-19
}

\author{
Navin G. Vigneshwar, MD • Martin Krause, MD • \\ Karsten Bartels, MD, PhD
}

Received: 25 May 2020 /Revised: 2 June 2020 / Accepted: 3 June 2020/Published online: 12 June 2020

(C) Canadian Anesthesiologists' Society 2020

\section{To the Editor,}

Perioperative guidelines for patients with suspected coronavirus disease (COVID-19) often rely on nasopharyngeal swab testing for the presence of severe acute respiratory syndrome coronavirus 2 (SARS-CoV-2) RNA. Herein, we report the case of a patient with three consecutive negative nasopharyngeal swab tests followed by a positive tracheal aspirate test for SARS-CoV-2 RNA (Figure 1). Consent for this report was given by the patient's healthcare power of attorney.

A 78-yr-old male with a history of smoking, chronic obstructive pulmonary disease, and anemia presented with respiratory insufficiency. Two weeks prior, the patient was diagnosed at an outside hospital with COVID-19 through a positive real-time polymerase chain reaction test (RTPCR). He continued to decompensate at his skilled nursing facility, eventually presenting to our emergency department. On admission, a viral respiratory panel and two nasopharyngeal swab SARS-CoV-2 RT-PCR tests separated by four hours were negative. With an increasing oxygen requirement and a chest radiograph revealing

N. G. Vigneshwar, MD

Division of Cardiothoracic Surgery, Department of Surgery,

University of Colorado School of Medicine, Aurora, CO, USA

M. Krause, MD

Department of Anesthesiology, University of Colorado School of Medicine, Aurora, CO, USA

K. Bartels, MD, PhD ( $ه)$.

Division of Cardiothoracic Surgery, Department of Surgery, University of Colorado School of Medicine, Aurora, CO, USA e-mail: karsten.bartels@ucdenver.edu

Department of Anesthesiology, University of Colorado School of Medicine, Aurora, CO, USA multifocal opacities, the patient was admitted to the inpatient COVID service.

On hospital day 1, the patient's hypoxia improved, and results from a repeat SARS-CoV-2 RT-PCR test from a nasopharyngeal swab were negative. On the morning of hospital day 2, the patient developed worsening hypoxia requiring $100 \%$ fraction of inspired oxygen delivered via high flow nasal cannula, and a repeat chest radiograph showed worsening patchy infiltrates. As he was presumed SARS-CoV-2-negative, levofloxacin and doxycycline were started for community-acquired pneumonia. As his oxygenation worsened, he was trialed on bi-level positive airway pressure ventilation but ultimately required endotracheal intubation. His post-intubation $\mathrm{PaO}_{2} / \mathrm{FiO}_{2}$ fraction was 85. A tracheal aspirate sample was collected for a repeat SARS-CoV-2 RT-PCR test. By hospital day 3, results of the fourth SARS-CoV-2 test were positive.

Negative RT-PCR results in SARS-CoV-2-positive patients range from $20 \%$ to $70 \%$. This variability in RTPCR results is attributed to the anatomic location and viral load of the sample, RNA stability, the duration of viral shedding, and technical limitations within the assay itself. $^{1-3}$ Particularly relevant to our experience, the highest positive test rates have been seen in bronchoalveolar lavage specimens (93\%), followed by sputum (72\%), and nasopharyngeal swabs (63\%), indicating that lower respiratory tract sampling may be optimal for serial testing in critically ill patients. ${ }^{1}$ For this patient, the outside hospital used a commercially available RT-PCR kit that tested for a combination of gene targets. These included SARS-CoV-2 replicase complex (ORF 1 ab), spike, and nucleocapsid genes. Our institution's clinical laboratory used several different assays to test for SARS-CoV-2. The first negative test resulted from a commercial assay that targeted the ORF 1 ab gene. The 


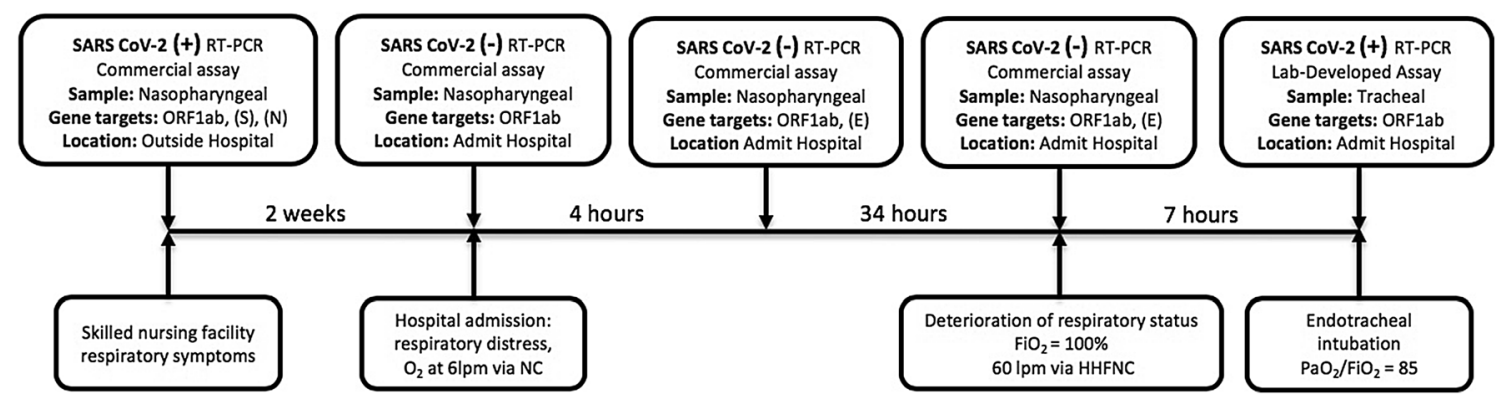

Figure 1 Timeline for the SARS-CoV-2 RNA testing in a patient with COVID-19. After testing positive for SARS-CoV-2 RNA from a nasopharyngeal sample two weeks prior to hospital admission, three negative nasopharyngeal SARS-CoV-2 RT-PCR tests were obtained. Following further deterioration of the patient's respiratory status and endotracheal intubation, a tracheal sample was positive for SARS-

second and third negative tests utilized a commercial assay that targets both the ORF 1 ab gene and the protein envelope $\mathrm{E}$ gene. The final positive test resulted from a laboratory-developed test that targeted the ORF $1 \mathrm{ab}$ gene. Early reports of SARS-CoV-2 testing indicate that different gene targets may have varying sensitivities and specificities. ${ }^{4}$ It is possible that this variability in testing kits may have impacted the yield of our nasopharyngeal samples.

Variability in testing is not limited to SARS-CoV-2, and, in part, can be explained by the viral load of the sample. During the novel influenza A (H1N1) pandemic, approximately $10 \%$ of patients showed positive RT-PCR test results in respiratory secretions after intubation when prior tests on nasopharyngeal swab gave negative results. ${ }^{5}$ Additionally, as we have seen during the SARS pandemic, RT-PCR is very susceptible to poor sample collection and degradation of the viral RNA sample.

The incidence of negative RT-PCR results in SARSCoV-2-positive patients is likely under-reported. An initial negative nasopharyngeal swab test should not alter clinical management in a patient showing the constellation of symptoms consistent with COVID-19. When feasible, serial lower respiratory tract samples should be collected to help confirm the diagnosis.

Disclosures None.
CoV-2 RNA. COVID-19 = coronavirus disease; $\mathrm{FIO}_{2}=$ fraction of inspired oxygen; $\mathrm{E}=$ protein envelope HFNC $=$ high-flow nasal cannula; $\mathrm{N}=$ nucleocapsid; $\mathrm{NC}=$ nasal cannula; $\mathrm{PaO}_{2}=$ arterial oxygen partial pressure; RT-PCR $=$ real-time polymerase chain reaction; $\mathrm{S}=$ spike; SARS-CoV-2 $=$ severe acute respiratory syndrome coronavirus 2 ; ORF1 $\mathrm{ab}=\mathrm{SARS}-\mathrm{CoV}-2$ replicase complex.

Funding statement None.

Editorial responsibility This submission was handled by Dr. Hilary P. Grocott, Editor-in-Chief, Canadian Journal of Anesthesia.

\section{References}

1. Wang W, Xu Y, Gao R, et al. Detection of SARS-CoV-2 in different types of clinical specimens. JAMA 2020; 323: 1843-4.

2. Wolfel R, Corman VM, Guggemos W, et al. Virological assessment of hospitalized patients with COVID-2019. Nature 2020; 581: 4659.

3. Ngaosuwankul N, Noisumdaeng P, Komolsiri P, et al. Influenza A viral loads in respiratory samples collected from patients infected with pandemic H1N1, seasonal H1N1 and H3N2 viruses. Virol J 2010; . https://doi.org/10.1186/1743-422X-7-75.

4. Nalla AK, Casto AM, Huang MW, et al. Comparative Performance of SARS-CoV-2 detection assays using seven different primerprobe sets and one assay kit. J Clin Microbiol 2020; 58: e0055720.

5. Rello J, Rodriguez A, Ibanez $P$, et al. Intensive care adult patients with severe respiratory failure caused by influenza A (H1N1)v in Spain. Crit Care 2009. DOI: https://doi.org/10.1186/cc8044.

Publisher's Note Springer Nature remains neutral with regard to jurisdictional claims in published maps and institutional affiliations. 